\title{
Detection and analysis of multiple biomarkers in ovarian cancer: clinical significance in diagnosis, treatment, and prognosis evaluation
}

\author{
Rui Ji ${ }^{1 \#}$, Yong $\mathrm{Li}^{1 \#}$, Chenyun $\mathrm{He}^{1}$, Xinghua $\mathrm{Zhu}^{2}$, Aiqin $\mathrm{He}^{1}$, Yunyan $\mathrm{Lu}^{1}$ \\ ${ }^{1}$ Department of Gynecology, Affiliated Cancer Hospital of Nantong University, Nantong, China; ${ }^{2}$ Department of Pathology, Affiliated Cancer \\ Hospital of Nantong University, Nantong, China \\ Contributions: (I) Conception and design: R Ji; (II) Administrative support: None; (III) Provision of study materials or patients: C He, Y Lu; (IV) \\ Collection and assembly of data: Y Li, A He; (V) Data analysis and interpretation: X Zhu; (VI) Manuscript writing: All authors; (VII) Final approval \\ of manuscript: All authors. \\ \#These authors contributed equally to this work. \\ Correspondence to: Aiqin He; Yunyan Lu. Department of Gynecology, Affiliated Cancer Hospital of Nantong University, Nantong, China. \\ Email: haq0118@163.com; 2425523985@qq.com.
}

Background: The purpose of this study was to explore the clinical significance of CA125, CK7, CK20, ER, PR, C-erbb2, and P-gp in ovarian cancer.

Methods: Ovarian cancer patients were recruited from Nantong Cancer Hospital between March 2006 and July 2011. The expressions of CA125, CK7, CK20, ER, PR, C-erbb2, and P-gp were determined by immunohistochemistry (IHC). The chi-square test $\left(\chi^{2}\right)$ was used to analyze the correlation between each index and the clinical characteristics of the patients. The patients were followed up to record the cancer recurrence time. The Kaplan-Meier method was used to map the cumulative recurrence-free survival (RFS) rate, and COX regression analysis was established for multivariate analysis.

Results: The results of IHC showed that the positive expression rates of CA125, CK7, ER, C-erbb2, and $\mathrm{P}$-gp in malignant ovarian cancer tissues were significantly higher than those in benign ovarian cancer tissues. CA125 expression in malignant ovarian cancer was significantly correlated with the age of patients and the Federation of International Gynecology and Obstetrics (FIGO) stage. CK7 expression in malignant ovarian cancer was significantly correlated with the age, tissue differentiation, and number of residual lesions. CK20 expression in malignant ovarian cancer was significantly correlated with the age and tissue differentiation of the patients. ER expression in malignant ovarian cancer was significantly correlated with the age of patients and FIGO stage. PR expression in malignant ovarian cancer was significantly correlated with the age of the patients. C-erbb2 expression in malignant ovarian cancer was significantly correlated with the age of the patients. $\mathrm{P}$-gp expression in malignant ovarian cancer was significantly correlated with the patient age, pathological type, and tissue differentiation. The expression of CA125, CK7, CK20, C-erbb2, and P-gp had significant effects on the prognosis of patients with ovarian cancer. The COX regression analysis showed that $P-g p$ was an independent risk factor for ovarian cancer.

Conclusions: In malignant ovarian cancer tissues, CA125, CK7, CK20, ER, PR, C-erbb2, and P-gp are over-expressed. The expression of $\mathrm{P}$-gp is an independent risk factor for ovarian cancer, and it can be an important target for the treatment of malignant ovarian cancer.

Keywords: Ovarian cancer; CA125; CK7; CK20; estrogen receptor (ER); progesterone receptor (PR); C-erbb2; P-gp; COX; Kaplan-Meier

Submitted Oct 19, 2020. Accepted for publication Dec 13, 2020.

doi: $10.21037 /$ gs-20-811

View this article at: http://dx.doi.org/10.21037/gs-20-811 


\section{Introduction}

The most common malignant tumors of the female reproductive system are cervical cancer, endometrial cancer, and ovarian cancer, of which ovarian cancer has the highest mortality rate $(1,2)$. During laparotomy of ovarian cancer patients, tumor tissue accounted for $30 \%$ of the ovary, and the majority had spread to the uterus, bilateral attachments, omentum, and pelvic organs. At present, there is no effective early diagnosis method. At the time of treatment, $70 \%$ of patients have reached the advanced stage, and the 5 -year survival rate is only about $30 \%(3,4)$. The exact diagnosis of ovarian cancer still presents a great challenge in clinical practice. No specific tumor markers for various ovarian cancer malignancies have been found to date. If specific indicators for detecting the malignant tumors of ovarian cancer could be found, they may not only help screen patients with high-risk factors, diagnose early ovarian cancer patients, monitor the therapeutic effect of ovarian cancer in real time, assess the prognosis, but could also be used to facilitate the selection of different chemotherapy regimens. Therefore, finding specific biomarkers for ovarian tumors would be significantly helpful.

Tumor markers are substances that are abnormally expressed in tumor cells. They are not expressed or lowly expressed in normal tissues, and can be used for the early diagnosis, efficacy detection, and prognosis evaluation of tumors. Cancer antigen 125 (CA125) is a glycoprotein that can be detected by epithelial ovarian cancer antigen, and can be bound by monoclonal antibody OC125 (5). It is widely used in the diagnosis of ovarian cancer $(6,7)$; however, subsequent studies have found that the detection of CA125 has a high false positive rate, and it also has different degrees of increase in other cancers such as breast, pancreatic, liver, and lung, which directly affects its specificity for the diagnosis of ovarian cancer. There is an objection to CA125 in the early diagnosis of ovarian cancer (8), but there is currently no tumor marker that can completely replace it as the first reference for the diagnosis of ovarian cancer. Therefore, in order to improve the sensitivity and specificity of early diagnosis of ovarian cancer, CA125 was simultaneously detected with a variety of tumor markers of different specificities, combined with clinical comprehensive judgment, in order to facilitate the diagnosis and treatment of ovarian cancer, according to the aim of this research.

In this study, immunohistochemistry (IHC) was used to simultaneously study the expressions of 7 indicators,
CA125, CK7, CK20, ER, PR, C-erbb2, and P-gp, in ovarian cancer tissues, to explore the correlation between each index and the clinical features of ovarian cancer, and provide a theoretical basis for the early diagnosis, treatment, and prognosis evaluation of ovarian cancer. We present the following article in accordance with the REMARK reporting checklist (available at http://dx.doi.org/10.21037/ gs-20-811).

\section{Methods}

\section{Population selection}

A total of 253 patients with primary ovarian cancer who were admitted to the Nantong Cancer Hospital from March 2006 and July 2011 were recruited, and all cases were confirmed by pathological or cytological diagnosis. The age of participants was $24-83$ years old, 64 cases were $<50$ years, 189 were $\geq 50$ years; the average age was $57 \pm 10$ years; 68 participants were not menopausal, and 185 were menopausal (defined as menopause for $>12$ months). Histological classification of participants was as follows: 86 cases of serous tumors, 16 cases of mucinous tumors, 15 cases of endometrioid tumors, and 136 cases of other cases; the degree of differentiation: 7 cases in moderately and highly differentiated group, and 111 cases in poorly differentiated group. Clinical staging was performed according to the Federation of International Gynecology and Obstetrics (FIGO): 55 cases in stage I/II, and 198 cases in stage III/IV. All patients had tumor tissue resected, the average operation time was $2.84 \mathrm{~h}$, and 253 specimens of ovarian cancer were gathered (Table 1). A total of 60 participants with benign ovarian disease diagnosed by pelvic color Doppler ultrasound in our hospital at the same time were selected. The obtained surgical resection specimens were used as the control group. The study was conducted in accordance with the Declaration of Helsinki (as revised in 2013). This study was approved the Ethics Committee of Nantong Tumor Hospital. Written informed consent was provided by all participants prior to tissue collection.

\section{Reagent}

Mouse anti-human CA125 monoclonal antibody (MA190039), mouse anti-human CK7 monoclonal antibody (MA5-15604), mouse anti-human CK20 monoclonal antibody (MA1-35556), mouse anti-human ER monoclonal antibody (MA5-13304), mouse anti-human PR monoclonal 
Table 1 Clinicopathological characteristics of ovarian cancer patients

\begin{tabular}{lc}
\hline Variable & Number \\
\hline Age (years) & 64 \\
$<50$ & 189 \\
$\geq 50$ & \\
Pathological type & 86 \\
Serous & 16 \\
Mucinous & 15 \\
Endometrioid & 136 \\
Others & \\
Tissue differentiation & 67 \\
High & 72 \\
Moderate & 111 \\
Low & \\
FIGO stage & \\
I-II & 55 \\
III-IV & 198 \\
Residual lesion & \\
0 & 53 \\
1 & \\
\hline
\end{tabular}

FIGO, Federation of International Gynecology and Obstetrics.

antibody (MA1-410), mouse anti-human C-erbb2 monoclonal antibody (MA5-13675), and mouse anti-human P-gp monoclonal antibody (MA5-13854) were purchased from Invitrogen (ThermoFisher, Waltham, MA, USA). The phosphate-buffered saline (PBS) solution was purchased from Sigma (Sigma Aldrich Corp., St. Louis, MO, USA); the 3,3'-diaminobenzidine (DAB) chromogenic reagent was purchased from Fuzhou Maxim Biotechnologies (Fuzhou, Fujian, China).

\section{Immunobistochemical (IHC)}

The IHC [streptomycin avidin-peroxidase ligation (SP)] was performed to detect protein expressions. Specimens were fixed in formaldehyde, embedded in paraffin, and serially sectioned at $5 \mu \mathrm{m}$. The sections were routinely dewaxed, immersed in a $\mathrm{pH}$ of 6.0 citrate buffer at a concentration of $0.01 \mathrm{~mol} / \mathrm{L}$, the antigen was repaired by microwave, then freshly prepared 3\% (volume fraction) $\mathrm{H}_{2} \mathrm{O}_{2}$ in distilled water, and incubated at room temperature for $10 \mathrm{~min}$. We then inactivated the endogenous peroxidase, added normal goat serum blocking solution, and incubated the sections for $20 \mathrm{~min}$ at room temperature. Primary antibodies were added at a concentration of $1: 50$ at $4{ }^{\circ} \mathrm{C}$ overnight. Rewarming was then performed at $37{ }^{\circ} \mathrm{C}$ for $1 \mathrm{~h}$. Biotinylated goat anti-mouse secondary antibody was added, followed by incubation at $37{ }^{\circ} \mathrm{C}$ for $45 \mathrm{~min}$. Biotinylated horseradish peroxidase-labeled streptomycin was added, followed by incubation at $37{ }^{\circ} \mathrm{C}$ for $30 \mathrm{~min}$. Color development was achieved with $\mathrm{DAB}$, hematoxylin was used to mildly counterstain, and the samples were then dehydrated, made to be transparent, and gum-coated. Instead of the primary antibody, PBS was used as a negative control.

\section{Result observations}

The IHC staining sections were observed under a microscope and images were taken. Image-Pro Plus 6.0 software (Media Cybernetics Co., Ltd., Rockville, MD, USA) was used to analyze CA125, CK7, CK20, ER, PR, $\mathrm{C}$-erbb2, and $\mathrm{P}$-gp expressions of IHC sections. We selected 5 fields of view (FOVs) under high power objective $(\times 400)$, the percentage of positive stained cells was recorded, and the IHC results were scored according to the staining range and staining intensity $(9,10)$. The staining ratio of positive cells was 1 in the range of $5-20 \%, 2$ in the range of $20-50 \%$, and 3 in the case of $>50 \%$; the cell color was 1 for light brown, 2 for brown, and 3 for dark brown. The sum of the above two additions represents the expression level of each indicator in ovarian cancer tissues. A total of 1-2 points indicated a weak positive $(+), 3-5$ points indicated a positive $(++)$, and 6 points indicated a strong positive $(+++)$; if the staining intensity was not significantly different from background $(<5 \%)$, the indication was negative (-).

\section{Statistical analysis}

The data were analyzed using the statistical software SPSS21.0 (SPSS, Inc., IBM, Chicago, IL, USA). The measurement data were expressed as $\left(\bar{x}_{ \pm} \mathrm{SD}\right)$. The count data were expressed by the number of cases (\%). The positive rate of each index was compared by $\chi^{2}$ test, and the survival curve was drawn using the Kaplan-Meier method. The log-rank method was used to compare the survival time of different blood types, and the prognostic factors of 
Table 2 Protein expressions in different ovarian cancer tissues

\begin{tabular}{|c|c|c|c|c|c|c|c|c|c|c|c|c|c|}
\hline Variable & \multicolumn{6}{|c|}{ Expressions in benign ovarian cancer tissues } & \multicolumn{6}{|c|}{ Expressions in malignant ovarian cancer tissues } & $P$ value \\
\hline CA125 & 60 & 54 & 6 & 0 & 0 & 10 & 253 & 6 & 42 & 2 & 0 & 88 & $<0.05$ \\
\hline CK7 & & 44 & 16 & 0 & 0 & 26.7 & & 2 & 46 & 0 & 1 & 95.9 & $<0.05$ \\
\hline CK20 & & 55 & 5 & 0 & 0 & 8.3 & & 32 & 4 & 0 & 0 & 11.1 & $>0.05$ \\
\hline PR & & 47 & 13 & 0 & 0 & 21.6 & & 95 & 19 & 8 & 5 & 26.4 & $>0.05$ \\
\hline C-erbb2 & & 59 & 1 & 0 & 0 & 1.7 & & 106 & 7 & 0 & 0 & 6.2 & $<0.05$ \\
\hline P-gp & & 57 & 3 & 0 & 0 & 5.0 & & 44 & 6 & 5 & 2 & 22.8 & $<0.05$ \\
\hline
\end{tabular}

-, negative; +, weak positive; ++, moderate positive; +++, strong positive. ER, estrogen receptor; PR, progesterone receptor.

ovarian cancer were analyzed by COX multivariate analysis. The difference was deemed statistically significant at $\mathrm{P}<0.05$.

\section{Results}

\section{Biomarker expressions in ovarian cancer tissues}

The results of IHC staining of 60 cases of benign ovarian cancer tissues and 253 cases of malignant ovarian cancer tissues showed that the positive rate of CA125 in benign ovarian cancer tissues was $10 \%$, and the positive rate in malignant ovarian cancer tissues was $88 \%$; the difference was statistically significant $(\mathrm{P}<0.05)$. The positive rate of CK7 in benign ovarian cancer tissues was $26.7 \%$, and the positive rate in malignant ovarian cancer tissues was $95.9 \%$; the difference was statistically significant $(\mathrm{P}<0.05)$. The positive rate of ER in benign ovarian cancer tissues was $18.3 \%$, and the positive rate in malignant ovarian cancer tissues was $55.8 \%$; the difference was statistically significant $(\mathrm{P}<0.05)$. The positive rate of CK20 in benign ovarian cancer tissues was $8.3 \%$, and the positive rate in malignant ovarian cancer tissues was $11.1 \%$; the difference was not significant $(\mathrm{P}<0.05)$. The positive rate of $\mathrm{PR}$ in benign ovarian cancer tissues was $21.6 \%$, and the positive rate in malignant ovarian cancer tissues was $26.4 \%$; the difference was not significant $(\mathrm{P}<0.05)$. The positive rate of $\mathrm{C}$-erbb2 in benign ovarian cancer tissues was $1.7 \%$, and the positive rate in malignant ovarian cancer tissues was $6.2 \%$; the difference was significant $(\mathrm{P}<0.05)$. The positive rate of $\mathrm{P}$-gp in benign ovarian cancer tissues was $5.0 \%$, and the positive rate in malignant ovarian cancer tissues was $22.8 \%$; the difference was statistically significant $(\mathrm{P}<0.05)$ (Table 2).

\section{Correlations between biomarker expressions in ovarian cancer and clinicopathological features}

After gathering data of biomarker expressions, the correlations between biomarker expressions in ovarian cancer and clinicopathological features were analyzed, and the results are shown in Tables 3 and 4. The expression of CA125 in malignant ovarian cancer was significantly correlated with the age of patients and FIGO stage $(\mathrm{P}<0.05)$, but not with pathological type, tissue differentiation degree, and number of residual lesions $(\mathrm{P}>0.05)$. The expression of CK7 in malignant ovarian cancer was significantly correlated with the age, tissue differentiation, and number of residual lesions $(\mathrm{P}<0.05)$, but not to pathological type and FIGO stage $(\mathrm{P}>0.05)$. The expression of CK20 in malignant ovarian cancer was significantly correlated with the age and tissue differentiation of participants $(\mathrm{P}<0.05)$, but with pathological type, FIGO stage, and number of residual lesions $(\mathrm{P}>0.05)$. The expression of $\mathrm{ER}$ in malignant ovarian cancer was significantly correlated with the age of patients and FIGO stage $(\mathrm{P}<0.05)$, but not to pathological type, degree of tissue differentiation, and number of residual lesions $(\mathrm{P}>0.05)$. The expression of $\mathrm{PR}$ in malignant ovarian cancer was significantly correlated with patient age $(\mathrm{P}<0.05)$, but not to pathological type, degree of tissue differentiation, FIGO stage, and number of residual lesions $(\mathrm{P}>0.05)$. The expression of $\mathrm{C}$-erbb2 in malignant ovarian cancer was significantly correlated with the age of participants $(\mathrm{P}<0.05)$, but not to pathological type, tissue differentiation degree, FIGO stage, and number of residual lesions $(\mathrm{P}>0.05)$. The expression of $\mathrm{P}$-gp in malignant ovarian cancer was significantly correlated with the age, pathological type, and tissue differentiation of the participants $(\mathrm{P}<0.05)$, but not 
Table 3 Relationship between CA125, CK7, CK20, and ER expressions and clinicopathological features

\begin{tabular}{|c|c|c|c|c|c|c|c|c|c|c|c|c|c|c|c|c|c|}
\hline Variable & $\mathrm{n}$ & \multicolumn{2}{|c|}{ CA125 } & $\begin{array}{l}\text { Positive } \\
\text { rate }(\%)\end{array}$ & $\mathrm{P}$ value & \multicolumn{2}{|c|}{ CK7 } & $\begin{array}{l}\text { Positive } \\
\text { rate (\%) }\end{array}$ & $P$ value & \multicolumn{2}{|c|}{ CK20 } & $\begin{array}{l}\text { Positive } \\
\text { rate (\%) }\end{array}$ & $P$ value & \multicolumn{2}{|c|}{ ER } & $\begin{array}{l}\text { Positive } \\
\text { rate (\%) }\end{array}$ & $P$ value \\
\hline Age (years) & & & & & $<0.05$ & & & & $<0.05$ & & & & $<0.05$ & & & & $<0.05$ \\
\hline$<50$ & 64 & 2 & 16 & 25 & & 1 & 14 & 21.9 & & 9 & 2 & 3.1 & & 20 & 24 & 37.5 & \\
\hline$\geq 50$ & 189 & 4 & 29 & 15.3 & & 1 & 33 & 17.9 & & 23 & 2 & 1.1 & & 37 & 54 & 28.6 & \\
\hline Serous & 86 & 0 & 11 & 12.8 & & 1 & 8 & 9.3 & & 3 & 0 & 0 & 0.5460 & 19 & 33 & 38.4 & 0.1430 \\
\hline Mucinous & 16 & 1 & 2 & 12.5 & & 1 & 2 & 12.5 & & 2 & 1 & 6.3 & & 7 & 2 & 12.5 & \\
\hline Endometrioid & 15 & 0 & 3 & 20 & & 0 & 3 & 20 & & 2 & 0 & 0 & & 3 & 4 & 26.7 & \\
\hline Others & 136 & 5 & 28 & 20.6 & & 0 & 34 & 25 & & 25 & 3 & 2.2 & & 28 & 33 & 24.3 & \\
\hline Moderate & 5 & 0 & 0 & 0 & & 0 & 0 & 0 & & 0 & 0 & 0 & & 0 & 2 & 40 & \\
\hline Low & 111 & 4 & 23 & 20.7 & & 0 & 28 & 25.2 & & 17 & 1 & 0.9 & & 26 & 36 & 32.4 & \\
\hline FIGO stage & & 0 & & & $<0.05$ & & & & 1.0000 & & & & 1.0000 & & & & $<0.05$ \\
\hline I-II & 55 & 2 & 5 & 9.1 & & 0 & 10 & 18.2 & & 6 & 1 & 1.8 & & 17 & 10 & 18.2 & \\
\hline III-IV & 198 & 4 & 39 & 19.7 & & 2 & 37 & 18.7 & & 26 & 3 & 1.5 & & 40 & 63 & 31.8 & \\
\hline Residual lesions & & & & & 0.6615 & & & & $<0.0001$ & & & & 0.4593 & & & & 0.4082 \\
\hline 0 & 53 & 0 & 5 & 9.4 & & 0 & 7 & 13.2 & & 3 & 1 & 1.9 & & 13 & 17 & 32.1 & \\
\hline 1 & 174 & 5 & 35 & 20.1 & & 1 & 35 & 20.1 & & 25 & 2 & 1.1 & & 40 & 54 & 31.0 & \\
\hline
\end{tabular}

-, negative; +, positive. ER, estrogen receptor; FIGO, federation of international gynecology and obstetrics.

with the FIGO stage and the number of residual lesions $(\mathrm{P}>0.05)$.

\section{Impact of biomarker expressions on the prognosis of ovarian cancer}

Kaplan-Meier curve was used to analyze the recurrencefree survival (RFS) in participants with malignant ovarian cancer. As shown in Figure $1 A, B, C$, and $D$, participants with negative expressions of CA125, CK7, C-erbb2, and $\mathrm{P}$-gp had significantly longer RFS time than those with positive expressions, all $\mathrm{P}<0.05$, while patients with negative expression of CK20 had significantly shorter RFS than those with positive expression, $\mathrm{P}<0.05$ (Figure 1E). However, the expressions of ER and PR had no significant effect on the RFS of malignant ovarian cancer patients, all $\mathrm{P}>0.05$ (Figure 1F, $G$ ).
The COX regression analyses were used to assess the association of biomarker expressions with RFS in malignant ovarian cancer patients (Table 5). The results showed that only $\mathrm{P}$-gp expression was an independent risk factor of cancer recurrence.

\section{Discussion}

In recent years, the survival rate of patients with ovarian cancer has increased, mainly due to timely and continuous progress in the surgical treatment of ovarian cancer, development and improvement of cancer medication, and screening and early detection of ovarian cancer (11); however, the 5-year survival rate of advanced ovarian cancer is still low (12). The prognosis of ovarian cancer depends largely its clinical stage (13); therefore, improved early diagnosis, screening sensitive indicators for disease 
Table 4 Relationship between PR, C-erbb2, and P-gp expressions and clinicopathological features

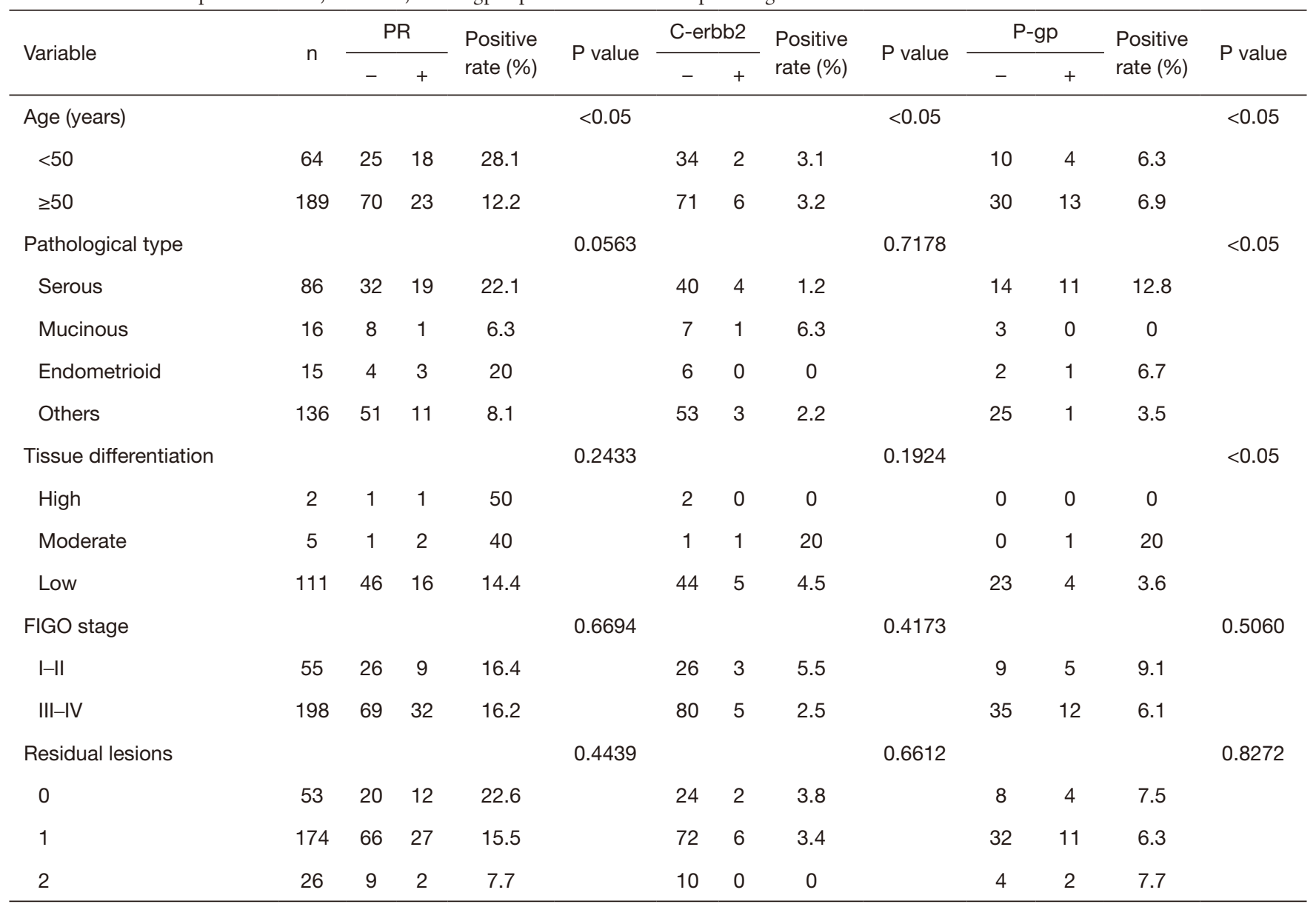

-, negative; +, positive. PR, progesterone receptor; FIGO, federation of international gynecology and obstetrics.

monitoring, and efficacy evaluation could become an important clinical reference for improving the survival rate of patients with ovarian cancer.

The antigen CA125 is a glycoprotein derived from the body cavity epithelium during embryonic development. In 1983, Bast et al. used monoclonal antibody technology to identify it from epithelial ovarian cancer antigens (14). Completely absent in normal ovarian tissue, CA125 is significantly elevated in the serum of patients with epithelial ovarian tumors. Accordingly, CA125 is used as an ovarian tumor marker for early diagnosis of ovarian cancer. The results of this study showed that the positive rate of CA125 in malignant ovarian cancer tissues was significantly higher than that in benign ovarian cancer tissues. The expression of CA125 in malignant ovarian cancer was correlated with the age of participants and FIGO stage, while it was not correlated with pathological type, degree of tissue differentiation, and number of residual lesions; that is, the positive rate of CA125 grew alongside the increase of patient clinical stage. From the Kaplan-Meier curve, the cumulative RFS rate of CA125-negative patients was higher than that of CA125-positive patients, indicating that the prognosis of patients with negative expression was better than that of positive patients, and positive expression of CA125 was correlated with recurrence in patients with ovarian cancer.

Cytokeratin (CK) is one of the cytoskeletal components, and its expression in epithelial cells varies with different lesions and tumor types. However, since the specific submicrostructural and immunological properties of the CK group of epithelial tissue can be maintained in the process of cell transformation, the application of appropriate CK, through the analysis of CK group, can help determine the direction of tumor differentiation and the histopathological 

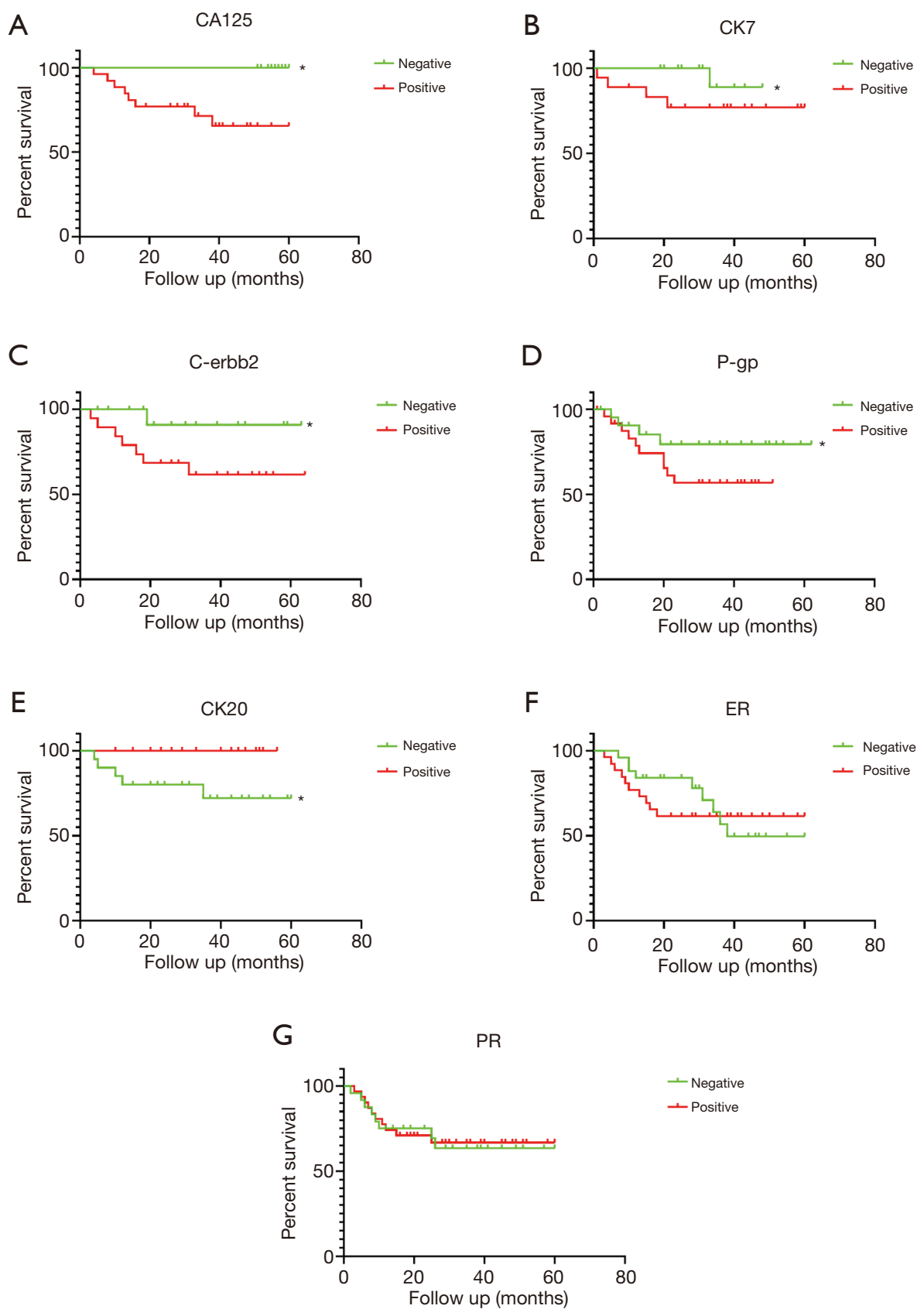

Figure 1 Kaplan-Meier curve of the RFS rate of 253 ovarian cancer patients. (A) CA125; (B) CK7; (C) C-erbb2; (D) P-gp; (E) CK20; (F) ER; (G) PR. * indicated that $\mathrm{P}<0.05$ compared to positive expression. RFS, recurrence-free survival; ER, estrogen receptor; PR, progesterone receptor.

tumor type $(15,16)$. The CK group member, CK7,can be extracted from human OTNII ovarian cancer cell lines, and is mainly labeled in glandular epithelium and transitional epithelium. Positive expression of CK may happen in the ovary, endometrium, mammary epithelium, lung, and mesothelial cells, and is generally negatively expressed in gastrointestinal-derived adenocarcinomas. It has been reported that $\mathrm{CK} 7$ is an effective marker for identifying primary ovarian and secondary colorectal adenocarcinoma $(17,18)$. An acidic keratin, CK20 is continuously positively 
Table 5 COX regression analysis

\begin{tabular}{|c|c|c|c|c|c|}
\hline Variable & $\beta$ & SE & Wald & $\mathrm{P}$ & $\mathrm{RR}$ \\
\hline CK7 & 0.586 & 0.286 & 1.053 & 0.391 & 1.835 \\
\hline CK20 & 0.564 & 0.282 & 4.6725 & 0.831 & 1.764 \\
\hline C-erbb2 & 0.612 & 0.320 & 1.140 & 0.944 & 1.711 \\
\hline
\end{tabular}

expressed when cells undergo deterioration, metastasis, invasion, and spread to other organ tissues $(19,20)$. The synthesis of CK20 first appeared in the intestinal mucosa of the 8th week of embryos. Single transformed monolayer epithelial cells, which are strictly epithelial tissue-specific, are currently recognized as specific tumor markers for the diagnosis of colorectal cancer micrometastasis (21). It has been reported in literature that differential expression of CK7 and CK20 can be used to identify primary ovarian cancer $(\mathrm{CK} 7+/ \mathrm{CK} 20-)$ and colon metastatic ovarian cancer (CK7-/CK20+) (22). Park et al. reported that the expression rates of CK7 and CK20 in 225 patients with colorectal cancer were $9 \%$ and $73 \%$, respectively, and 10 of 11 colorectal metastatic ovarian cancers were CK7-/CK20+; only 1 case showed $\mathrm{CK} 7+/ \mathrm{CK} 20-$, which meant that the primary ovarian cancer generally presented as CK7-/ CK20+ (23). The 253 ovarian cancer participants included in this study were primary ovarian cancer, of which the CK7 positive rate was $95.9 \%$, CK20 positive rate was $11.1 \%$, and $\mathrm{CK} 7+/ \mathrm{CK} 20$ - was present, which was consistent with the above results. Analysis of the relationship between CK7 and CK20 and clinical features showed that the expression of CK7 in malignant ovarian cancer was related to the age, tissue differentiation, and number of residual lesions of the participants. The expression of CK20 in malignant ovarian cancer was related to the participant age and tissue differentiation. It can be seen from the Kaplan-Meier curve that the cumulative recurrence rate of patients with negative expression of CK7 was higher than that of patients with positive expression, indicating that the prognosis of patients with negative expression was better than that of patients with positive expression. On the contrary, the prognosis of patients with positive expression of CK20 is better than that of those with negative expression, and we conclude that the positive expression of CK7 is associated with recurrence in postoperative patients with ovarian cancer. There are few studies on the correlation between CK20 and postoperative recurrence of ovarian cancer. Our study demonstrated that negative expression of CK20 was probably associated with recurrence in patients with postoperative ovarian cancer.

In normal ovarian tissue, estrogen receptor (ER) regulates tissue development and differentiation, and has mutagenic effects; progesterone receptor (PR) stimulates tissue development at lower concentrations, inhibits tissue development, induces apoptosis, and resists the mutagenic effects of estrogen at higher concentrations $(24,25)$. In recent years, it has been found that estrogen, progesterone, and their receptors have different relationships with other tumors in the development, treatment, and prognosis of female tumors. The ovaries are the organs responsible for producing sex hormones and the target organs of sex hormones, estrogen and progesterone, and their receptors. How this affects the occurrence and development of ovarian cancer is one of the hotspots of current research (26). Domestic and international reports on the relationship between ER, PR, and clinicopathological features of ovarian cancer are inconsistent. Domestic studies have found that the positive expression rate of ER and $\mathrm{PR}$ in ovarian cancer has nothing to do with pathological type, clinical stage, and differentiation degree. Another study reported that the positive rate of ER and PR in malignant ovarian cancer decreased with the increase of clinical stage. Langdon et al. found that the positive expression of $\mathrm{PR}$ in ovarian cancer in stage I/II was higher than that in stage III/IV, and that expression in the endometrium was higher than that of other tumor subtypes (27). Høgdall et al. pointed out that the positive rate of ER in ovarian cancer was positively correlated with clinical stage, and the positive expression rate of PR increases with the degree of differentiation (28). In this study, the ER-positive expression rate in malignant ovarian cancer was significantly higher than that in benign ovarian cancer. The positive expression rate of ER was related to participant age and clinical stage of ovarian cancer. The expression of ER increased with clinical 
stage, but not with pathological type, degree of tissue differentiation, and number of residual lesions. There was no significant difference in the positive expression rate of PR between malignant and benign ovarian tissue. The expression rate of $\mathrm{PR}$ was related to the age of ovarian cancer patients, but not to clinical stage, pathological type, degree of tissue differentiation, and number of residual lesions. Analysis of Kaplan-Meier curve found that ER, PR positive expression, and malignant ovarian cancer prognosis had no significant correlations. Because the positive expression rate of $\mathrm{ER}$ and $\mathrm{PR}$ is not different in the pathological type of ovarian cancer, ER and PR are limited in identifying the pathological types of ovarian cancer, and an ER and PR single test confirmed that there was no significant correlation between them and the prognosis of patients with malignant ovarian cancer, which limited the analysis and speculation of the prognosis of the participants. The positive expression rate of ER varies in different clinical stage, suggesting that ER can be used as an indicator of tumor stage and a feature of tumor cells. The increase of expression is related to tumor formation. Formelli et al. demonstrated through animal experiments that PR can effectively resist the transplantation of human ovarian cancer cells in mice (29). The proliferation of different cancer cell lines is inhibited by PR via the induction of apoptosis in vitro, including that of leukocytes, optic neuroblastoma cells, and others (30-32), and thus is widely used clinically to treat various cancers. In ovarian tissue, when the PR concentration is too high, it induces apoptosis, suggesting that induction of apoptosis may be one of the key roles of progesterone in the treatment of ovarian cancer (33). Münstedt $e t$ al. studied the distribution and combination of ER/PR in participants with ovarian cancer $(\mathrm{ER}+\mathrm{PR}+$, $\mathrm{ER}+\mathrm{PR}-, \mathrm{ER}-\mathrm{PR}+, \mathrm{ER}-\mathrm{PR}-)$, and found that the groups containing $\mathrm{PR}+$ had a better prognosis than those with $\mathrm{PR}-$ combinations, and that the combination of ER-PR+ had an especially good prognosis, it can be seen that PR promoted cancer cell differentiation and apoptosis (34). The combined detection of ER and PR plays an important role in diagnosis of progression, distant metastasis, and prognosis of ovarian cancer, and the effect of both on ovarian cancer is opposite, that is, high expression of ER promotes the proliferation of ovarian cancer cells (35), while PR plays a protective role in the development of tumors and can prevent the development of cancer.

The $C$-erbb2 gene is a member of the epidermal growth factor receptor (EGFR) family and plays an important role in cell signaling. It is an important regulator of cell growth, differentiation, and survival. Under normal conditions, $\mathrm{C}$-erbb2 is in an inactive state and participates in the mediation of cell differentiation. It is activated by gene amplification and becomes an activated oncogene, which promotes cell carcinogenesis and cancer cell growth and proliferation $(36,37)$. Studies have shown that the amplification and overexpression of the $C$-erbb2 gene is closely related to the occurrence and development of ovarian cancer and patient prognosis (38). Hattori et al. have shown that amplification of the $C$-erbb2 gene and overexpression of the C-erbb2 protein can be used as markers for the poor prognosis of ovarian cancer (39). Ross et al. used fluorescence in situ hybridization to detect the expression of $\mathrm{C}$-erbb2 in different stages and pathological types of ovarian cancer, but the results showed no significant difference (40). The results of this study showed that the positive expression rate of C-erbb2 in malignant ovarian cancer was significantly higher than that of benign ovarian cancer, and it can be used as a tumor marker for malignant ovarian cancer. Its expression is independent of the pathological type of the patient, degree of tissue differentiation, FIGO stage, and the number of residual lesions. Therefore, it will be limited in accurately determining the pathological type and differentiation, while combining C-erbb2 with other tumor markers should be considered to improve the accuracy of diagnosis. Analysis of the Kaplan-Meier curve showed that patients with negative C-erbb2 expression had better prognoses than those with positive expression, and it was concluded that positive expression of $\mathrm{C}$-erbb2 was associated with recurrence in postoperative ovarian cancer patients.

It is well-recognized that $\mathrm{P}-\mathrm{gp}$ is an indicator for measuring the efficacy of chemotherapy in tumor cells. This has been verified not only in female reproductive system malignancies, but also in other tumor cells. In general, the higher the cellular expression level of P-gp, the worse the chemotherapy effect, and the worse the prognosis and survival time of patients. The mechanism by which P-gp causes drug resistance in tumor cells is by combining with chemotherapeutic drugs which differ in structure and mechanism and discharging them from cells. Drugs are redistributed into unrelated organelles, diminishing drug concentration at the target site, which in turn leads to the development of drug resistance in tumor cells (41). Kavallaris et al. demonstrated in experiments that high expression of $\mathrm{P}$-gp can significantly reduce patient sensitivity to chemotherapy drugs (42). However, there have also been reports of the opposite: Joncourt et al. 
used western blot hybridization to detect the expression of P-gp in 39 ovarian cancer tissues, and the results showed that its expression was not associated with chemotherapy sensitivity (43). In this study, IHC was used to analyze the expression of $\mathrm{P}$-gp in patients of different pathological types, different degrees of tissue differentiation, different FIGO stages, and different number of residual lesions. It was found that the positive expression rate of $\mathrm{P}$-gp in serous ovarian cancer was higher than other pathological types. The expression rate of $\mathrm{P}$-gp in moderately/highly differentiated malignant ovarian cancer tissues was significantly higher than that in poorly differentiated tissues, and the lower the FIGO stage, the higher the expression of $\mathrm{P}-\mathrm{gp}$ in tissues, but the difference was not statistically significant. Analysis of the Kaplan-Meier curve found that patients with negative P-gp expression had better prognoses than those with positive expression, and it was concluded that $\mathrm{P}$-gp positive expression was associated with recurrence in postoperative ovarian cancer patients. Finally, according to COX regression analysis, it was concluded that $\mathrm{P}$-gp is an independent risk factor for ovarian cancer.

In summary, it can be concluded that there is a correlation between the CA125, CK7, CK20, C-erbb2, and $\mathrm{P}$-gp expressions in ovarian cancer tissues and the prognosis of ovarian cancer patients, and P-pg is an independent risk factor for the prognosis of ovarian cancer patients. However, due to the small samples and short duration of study in this research, there are still some shortcomings, further studies need to expand sample size and increase follow-up period.

\section{Acknowledgments}

Funding: The study was supported by Nantong Municipal Health Committee (WKZL2018088) and Nantong University (2019LY032).

\section{Footnote}

Reporting Checklist: The authors have completed the REMARK reporting checklist. Available at http:// dx.doi.org/10.21037/gs-20-811

Data Sharing Statement: Available at http://dx.doi. org/10.21037/gs-20-811

Conflicts of Interest: All authors have completed the ICMJE uniform disclosure form (available at http://dx.doi. org/10.21037/gs-20-811). The authors have no conflicts of interest to declare.

Ethical Statement: The authors are accountable for all aspects of the work in ensuring that questions related to the accuracy or integrity of any part of the work are appropriately investigated and resolved. The study was conducted in accordance with the Declaration of Helsinki (as revised in 2013). This study was approved the Ethics Committee of Nantong Tumor Hospital. Written informed consent was provided by all participants prior to tissue collection.

Open Access Statement: This is an Open Access article distributed in accordance with the Creative Commons Attribution-NonCommercial-NoDerivs 4.0 International License (CC BY-NC-ND 4.0), which permits the noncommercial replication and distribution of the article with the strict proviso that no changes or edits are made and the original work is properly cited (including links to both the formal publication through the relevant DOI and the license). See: https://creativecommons.org/licenses/by-nc-nd/4.0/.

\section{References}

1. Miller KD, Goding Sauer A, Ortiz AP, et al. Cancer Statistics for Hispanics/Latinos, 2018. CA Cancer J Clin 2018;68:425-45.

2. Siegel RL, Miller KD, Jemal A. Cancer statistics, 2019. CA Cancer J Clin 2019;69:7-34.

3. Zhou S, Liu Y, Yin W, et al. Clinicopathologic factors associated with short-term survival in advanced epithelial ovarian cancer. Transl Cancer Res 2019;8:2396-404.

4. Hensley ML. A step forward for two-step screening for ovarian cancer. J Clin Oncol 2010;28:2128-30.

5. Kabawat SE, Bast RC Jr, Bhan AK, et al. Tissue distribution of a coelomic-epithelium-related antigen recognized by the monoclonal antibody OC125. Int J Gynecol Pathol 1983;2:275-85.

6. Bast RC Jr, Spriggs DR. More than a biomarker: CA125 may contribute to ovarian cancer pathogenesis. Gynecol Oncol 2011;121:429-30.

7. Bast RC Jr, Skates S, Lokshin A, et al. Differential diagnosis of a pelvic mass: improved algorithms and novel biomarkers. Int J Gynecol Cancer 2012;22 Suppl 1:S5-8.

8. Cohen LS, Escobar PF, Scharm C, et al. Threedimensional power Doppler ultrasound improves the 
diagnostic accuracy for ovarian cancer prediction. Gynecol Oncol 2001;82:40-8.

9. Wang L, Rambau PF, Kelemen LE, et al. Nuclear betacatenin and CDX2 Expression in Ovarian Endometrioid Carcinoma Identify Patients with Favorable Outcome. Histopathology 2019;74:452-62.

10. He Y, Wang H, Yan M, et al. High LIN28A and PLK4 coexpression is associated with poor prognosis in epithelial ovarian cancer. Mol Med Rep 2018;18:5327-36.

11. Schummer M, Ng WV, Bumgarner RE, et al. Comparative hybridization of an array of 21,500 ovarian cDNAs for the discovery of genes overexpressed in ovarian carcinomas. Gene 1999;238:375-85.

12. Siegel RL, Miller KD, Jemal A. Cancer Statistics, 2017. CA Cancer J Clin 2017;67:7-30.

13. Gorodnova TV, Sokolenko AP, Kuligina E, et al. Principles of clinical management of ovarian cancer. Chin Clin Oncol 2018;7:56.

14. Bast RC Jr, Klug TL, St John E, et al. A radioimmunoassay using a monoclonal antibody to monitor the course of epithelial ovarian cancer. N Engl J Med 1983;309:883-7.

15. Chu P, Wu E, Weiss LM. Cytokeratin 7 and cytokeratin 20 expression in epithelial neoplasms: a survey of 435 cases. Mod Pathol 2000;13:962-72.

16. Han J, Kim MK, Nam SJ, et al. E-cadherin and cytokeratin subtype profiling in effusion cytology. J Korean Med Sci 2004;19:826-33.

17. Chan ES, Alexander J, Swanson PE, et al. PDX-1, CDX2, TTF-1, and CK7: a reliable immunohistochemical panel for pancreatic neuroendocrine neoplasms. Am J Surg Pathol 2012;36:737-43.

18. McCluggage WG, Wilkinson N. Metastatic neoplasms involving the ovary: a review with an emphasis on morphological and immunohistochemical features. Histopathology 2005;47:231-47.

19. Ji H, Isacson C, Seidman JD, et al. Cytokeratins 7 and 20, Dpc4, and MUC5AC in the distinction of metastatic mucinous carcinomas in the ovary from primary ovarian mucinous tumors: Dpc4 assists in identifying metastatic pancreatic carcinomas. Int J Gynecol Pathol 2002;21:391-400.

20. Ketelaar T, Faivre-Moskalenko C, Esseling JJ, et al. Positioning of nuclei in Arabidopsis root hairs: an actin-regulated process of tip growth. Plant Cell 2002;14:2941-55.

21. Cathro HP, Stoler MH. Expression of cytokeratins 7 and 20 in ovarian neoplasia. Am J Clin Pathol 2002;117:944-51.
22. Raspollini MR, Amunni G, Villanucci A, et al. Utility of CDX-2 in distinguishing between primary and secondary (intestinal) mucinous ovarian carcinoma: an immunohistochemical comparison of 43 cases. Appl Immunohistochem Mol Morphol 2004;12:127-31.

23. Park SY, Kim HS, Hong EK, et al. Expression of cytokeratins 7 and 20 in primary carcinomas of the stomach and colorectum and their value in the differential diagnosis of metastatic carcinomas to the ovary. Hum Pathol 2002;33:1078-85.

24. McDonnel AC, Van Kirk EA, Isaak DD, et al. Inhibitory effects of progesterone on plasma membrane fluidity and tumorigenic potential of ovarian epithelial cancer cells. Exp Biol Med (Maywood) 2003;228:308-14.

25. Ho SM. Estrogen, progesterone and epithelial ovarian cancer. Reprod Biol Endocrinol 2003;1:73.

26. Sallum LF, Sarian LO, Lucci De Angelo Andrade L, et al. Survival of women with ovarian carcinomas and borderline tumors is not affected by estrogen and progesterone receptor status. J Gynecol Oncol 2013;24:167-76.

27. Langdon SP, Gabra H, Bartlett JM, et al. Functionality of the progesterone receptor in ovarian cancer and its regulation by estrogen. Clin Cancer Res 1998;4:2245-51.

28. Høgdall EV, Christensen L, Hogdall CK, et al. Prognostic value of estrogen receptor and progesterone receptor tumor expression in Danish ovarian cancer patients: from the 'MALOVA' ovarian cancer study. Oncol Rep 2007;18:1051-9.

29. Formelli F, Cleris L. Therapeutic effects of the combination of fenretinide and all-trans-retinoic acid and of the two retinoids with cisplatin in a human ovarian carcinoma xenograft and in a cisplatin-resistant sub-line. Eur J Cancer 2000;36:2411-9.

30. Marth C, Daxenbichler G, Dapunt O. Synergistic antiproliferative effect of human recombinant interferons and retinoic acid in cultured breast cancer cells. J Natl Cancer Inst 1986;77:1197-202.

31. Chen ZX, Xue YQ, Zhang R, et al. A clinical and experimental study on all-trans retinoic acid-treated acute promyelocytic leukemia patients. Blood 1991;78:1413-9.

32. Formelli F, Carsana R, Costa A, et al. Plasma retinol level reduction by the synthetic retinoid fenretinide: a one year follow-up study of breast cancer patients. Cancer Res 1989;49:6149-52.

33. Moon RC, Mehta RG, Detrisac CJ. Retinoids as chemopreventive agents for breast cancer. Cancer Detect Prev 1992;16:73-9.

34. Münstedt K, Steen J, Knauf AG, et al. Steroid hormone 
receptors and long term survival in invasive ovarian cancer. Cancer 2000;89:1783-91.

35. Syed V, Ulinski G, Mok SC, et al. Expression of gonadotropin receptor and growth responses to key reproductive hormones in normal and malignant human ovarian surface epithelial cells. Cancer Res 2001;61:6768-76.

36. Blume-Jensen P, Hunter T. Oncogenic kinase signalling. Nature 2001;411:355-65.

37. Kawamura K, Komohara Y, Takaishi K, et al. Detection of M2 macrophages and colony-stimulating factor 1 expression in serous and mucinous ovarian epithelial tumors. Pathol Int 2009;59:300-5.

38. Felip E, Del Campo JM, Rubio D, et al. Overexpression of c-erbB-2 in epithelial ovarian cancer. Prognostic value and relationship with response to chemotherapy. Cancer 1995;75:2147-52.

39. Hattori M, Sakamoto H, Satoh K, et al. DNA demethylase is expressed in ovarian cancers and the expression

Cite this article as: Ji R, Li Y, He C, Zhu X, He A, Lu Y. Detection and analysis of multiple biomarkers in ovarian cancer: clinical significance in diagnosis, treatment, and prognosis evaluation. Gland Surg 2020;9(6):2175-2186. doi: 10.21037/gs-20811 correlates with demethylation of $\mathrm{CpG}$ sites in the promoter region of c-erbB-2 and survivin genes. Cancer Lett 2001;169:155-64.

40. Ross JS, Yang F, Kallakury BV, et al. HER-2/neu oncogene amplification by fluorescence in situ hybridization in epithelial tumors of the ovary. Am J Clin Pathol 1999;111:311-6.

41. Volm M, Koomagi R, Mattern J, et al. Protein expression profiles indicative for drug resistance of non-small cell lung cancer. Br J Cancer 2002;87:251-7.

42. Kavallaris M, Leary JA, Barrett JA, et al. MDR1 and multidrug resistance-associated protein (MRP) gene expression in epithelial ovarian tumors. Cancer Lett 1996;102:7-16.

43. Joncourt F, Buser K, Altermatt H, et al. Multiple drug resistance parameter expression in ovarian cancer. Gynecol Oncol 1998;70:176-82.

(English Language Editor: J. Jones) 